\title{
Effect of supplementary niacin on in vitro ruminal organic matter fermentation and microbial $\mathbf{N}$ synthesis in cows
}

\author{
M Doreau, JF Ottou
}

\author{
INRA, Laboratoire Sous-Nutrition des Ruminants, Theix, 63122 St-Genès-Champanelle, France
}

\begin{abstract}
Niacin supplementation for dairy cow diets may enhance ruminal fermentation and microbial synthesis, but the response is inconsistent from a trial to another (reviews by Harmeyer and Kollenkirchen, 1989, Nutr Res Rev, 2, 201225, and by Flachowsky, 1993, Arch Anim Nutr, 43, 195-213). Response to supplementary niacin could depend on the diet, but very few experiments have directly studied the interaction between type of diet and supplementary niacin. The aim of this trial was to evaluate the effect of niacin on ruminal fermentation and microbial synthesis, either on a high-energy diet or on a low-energy diet.
\end{abstract}

An in vitro trial was performed using a closed fermenter, according to Jouany and Thivend (1986, Anim Feed Sci Technol, 15, 225-229). Ruminal contents $(200 \mathrm{~g})$ were incubated at $39^{\circ} \mathrm{C}$ for $5 \mathrm{~h}$ with $200 \mathrm{ml}$ buffer, a $\mathrm{N}$ source in sufficient amount, $13 \mathrm{~g}$ pure starch as energy source, and either no niacin or $64 \mathrm{mg}$ niacin. Ruminal contents were obtained either from two dry cows fed a diet rich in maize silage and concentrates (diet MS-C), made of (on DM basis) $56 \%$ maize silage, $29 \%$ energy concentrate, $9 \%$ soybean meal, $5 \%$ hay and $1 \%$ mineral premix, or from two dry cows fed a diet containing on DM basis $91 \%$ hay, $8 \%$ soybean meal and $1 \%$ mineral premix (diet $\mathrm{H}$ ).
Five successive series of fermentation trials were performed. Volatile fatty acid production (VFA) was determined by gas chromatography and allowed to calculate fermentable organic matter (FOM) using a stoechiometric equation ; microbial synthesis was estimated from the decrease in ammonia- $\mathrm{N}$ concentration between 1 and $5 \mathrm{~h}$ of fermentation; the efficiency of microbial synthesis (EMS) was the ratio between FOM and ammonia- $\mathrm{N}$ uptake. Statistical analyses were performed using a two-way analysis of variance with interaction.

Although non significant $(P>0.10)$, a trend to an increased VFA production with added niacin occurred. Among VFA, only butyrate was significantly enhanced $(P<0.05)$, due to an increase with MS-C diet (significant interaction, $P<0.05)$. Niacin increased FOM $(P<0.10)$ but this effect was observed only with MS-C diet (significant interaction, $P<0.10$ ). Niacin increased ammonia $N$ uptake $(P<0.05)$, but no interaction with diet was noted $(P>0.10)$. Niacin supply did not modify EMS $(P>0.10)$ whatever the diet. The particular effect of supplementary niacin for diet MS-C could be due to a higher requirement for niacin with highly fermentable diets, as in a trial by Schussler et al (1978, Int J Vit Nutr Res, 48, 359-367). These results have now to be sustained by in vivo data.
Nature of the diet

VFA production (mmol)

Acetate

Propionate

Butyrate

FOM (g)

Ammonia N uptake $(\mathrm{mg} / \mathrm{l})$

$\operatorname{EMS}(\mathrm{mg} / \mathrm{g})$

\begin{tabular}{|c|c|c|c|}
\hline \multicolumn{2}{|c|}{ MS-C } & \multicolumn{2}{|c|}{$\mathrm{H}$} \\
\hline Control & Niacin & Control & Niacin \\
\hline 17.9 & 20.5 & 12.1 & 11.1 \\
\hline 9.2 & 10.7 & 3.4 & 3.5 \\
\hline 5.4 & 7.7 & 2.3 & 2.5 \\
\hline 3.36 & 4.19 & 1.57 & 1.59 \\
\hline 126.4 & 155.8 & 53.8 & 55.3 \\
\hline 15.0 & 14.6 & 13.7 & 15.0 \\
\hline
\end{tabular}

